community patients were admitted to the acute inpatient setting. We therefore audited the standards relating to inpatient care which included the need to record the cause of neurodisability on admission, on daily ward rounds and at discharge, recording of a child's mobility, communication and if a child had a handheld patient record (or if one was recommended). Methods We retrospectively audited 30 children admitted over a 1 year period, randomly selecting 10 elective admissions, 10 emergency admissions with short stay spells ( $<24$ hours) and 10 longer term emergency admissions ( $>24$ hours). Baseline data is shown in the table 1 . Our short-term interventions following baseline data collection included delivering teaching to all ward doctors about the children with neurodisability \& why these aspects of care were important to record and attaching a prompt sheet to notes trolleys. A re-audit of 10 patients over the next 2 months (limited numbers due to reduced summer admissions) showed improvement in all areas. Results

\begin{tabular}{lll}
\hline Abstract G33 Table 1 & & \\
\hline & $\begin{array}{l}\text { Baseline } \\
\text { (30 patients) }\end{array}$ & $\begin{array}{l}\text { After Intervention } \\
\text { (10 patients) }\end{array}$ \\
\hline Cause of neurodisability recorded: & & \\
On Admission & $87 \%$ & $100 \%$ \\
Daily Summary & $60 \%$ & $90 \%$ \\
In discharge documentation & $67 \%$ & $100 \%$ \\
Mobility Recorded & $3.3 \%$ & $60 \%$ \\
Mode of Communication recorded & $6.6 \%$ & $50 \%$ \\
Patient Held Record (had or offered) & $10 \%$ & $60 \%$ \\
\hline
\end{tabular}

Conclusions Our short term intervention, which did not require any hospital committee approval or funding, showed significant improvement in our documentation towards the NCEPOD standards allowing us to better support these families. We have also designed a proforma for medical notes which is in the process of going through health records approval and will be re-audited once introduced.

\section{G34 UK CHILDREN WITH PROGRESSIVE NEUROLOGICAL DISEASE: DIFFERENTIAL DIAGNOSES BY AGE}

CM Verity, E Baker, PJ Maunder, AM Winstone. PIND Research Group, Addenbrooke's Hospital, Cambridge, UK

\subsection{6/archdischild-2020-rcpch.23}

Aims To review the cases referred to this UK-wide study of children with progressive intellectual and neurological deterioration (PIND) and analyse the differential diagnoses in these children by age at presentation.

Methods Children meeting the case definition for PIND were identified via the British Paediatric Surveillance Unit. Data were obtained by standard questionnaire, with additional information from hospital records and laboratory reports, allowing validation of diagnoses and estimation of the age of presentation to clinicians.

Results Between April 1997 and October 2019, 4612 children had been notified to the study. 2072 were found not to meet the PIND case definition. 2009 had an underlying diagnosis to explain their deterioration; of these the numbers presenting by age were: <1 year 805 (40\%), 1-4 years: 825 (41\%), 5-9 years 265 (13\%), 10-15 years 114 (6\%), with over 220 different disorders including 6 cases of variant Creutzfeldt-Jakob disease (vCJD) (the last identified in 2000). The children who presented aged 10-15 years included the 6 vCJD cases. Of the other disorders in this age group the commonest were: mitochondrial cytopathy (mito) 17, adrenoleukodystrophy (ALD) 9, Lafora body disease 8, Niemann-Pick type C 8, Huntington's disease 7, neuronal-ceroid lipofuscinoses (NCL) 7, SSPE 5, metachromatic leukodystrophy 4, Wilson's disease 4. The distribution of disorders varied with age e.g. the 3 commonest disorders in the other age groups were - 5-9 years: NCL, ALD, mito; 1-4 years: NCL, mucopolysaccharidosis III, mito; < 1 year: mito, GM2-gangliosidosis, Krabbe's disease.

Conclusion Since 1997 the PIND Study has provided unique epidemiological data about neurodegenerative diseases in UK children. It shows that children meeting the criteria for PIND tend to present early in life (over $80 \%$ before the age of 5 years) - not surprising because of the inherited basis for so many of these disorders. The study provides a differential diagnosis for PIND children by age and remains the only means of performing systematic surveillance of the neurodegenerative diseases that make up the differential diagnosis of vCJD. Acknowledgement Independent research funded by the Department of Health (DH) Policy Research Programme [PR-ST1216-10001]. Views expressed are not necessarily those of DH.

\section{G35 NATIONAL SURVEILLANCE OF SEVERE MICROCEPHALY DIAGNOSED IN INFANTS IN THE UNITED KINGDOM AND IRELAND}

${ }^{1}$ RL Knowles, ${ }^{1} \mathrm{M}$ Sampaio, ${ }^{1} \mathrm{AL}$ Solebo, ${ }^{2} \mathrm{~J}$ Sargent, ${ }^{2} \mathrm{~N}$ Oluonye, ${ }^{1} \mathrm{JS}$ Rahi. ${ }^{1}$ Population Policy and Practice Research and Teaching Department, UCL Great Ormond St Institute of Child Health, London, UK; ${ }^{2}$ Neurodisability, Great Ormond St Hospital for Children NHS FT, London, UK

\subsection{6/archdischild-2020-rcpch.24}

Background Severe microcephaly is defined by WHO as a head circumference (HC) more than 3 standard deviations below mean $(<-3 S D)$ for age and sex. Although UK congenital anomaly registrations suggest microcephaly is uncommon, there is uncertainty about the number of babies affected each year. To monitor emerging infections, such as Zika Virus, and understand the impact on health and neurodevelopment, it is essential to characterise the current burden of disease.

Aim To report the incidence, characteristics and causes of severe microcephaly diagnosed in children aged under one year in the UK and Ireland.

Methods Active surveillance through the British Paediatric Surveillance Unit for 13 months from October 2017 to ascertain all live born children aged under 1 year who were diagnosed during this period with microcephaly or noted to have a HC $<-3$ SD or $<0.4$ th percentile for age and sex, excluding babies with anencephaly. Clinicians who reported a child completed a clinical questionnaire.

The annual incidence of severe microcephaly was calculated for infants with $\mathrm{HC}<-3 \mathrm{SD}$ for age and sex. For all other analyses, children with $\mathrm{HC}<0.4$ th percentile were also included. All reported findings are based on confirmed cases to date.

Results The annual incidence of severe microcephaly (HC <3SD) between November 2017 and October 2018 was 5.6 